\title{
Effects of arsenic on wnt/ $\beta$-catenin signaling pathway: A systematic review and meta-analysis
}

\author{
Shugang $\mathrm{Li}^{1,+, *}$ Qingxin Ren ${ }^{2,+}$ \\ ${ }^{1}$ Department of Child, Adolescent Health and Maternal Health, School of Public Health, \\ Capital Medical University, Beijing 100069, China \\ ${ }^{2}$ Department of Public Health, College of Medicine, Shihezi University, Shihezi 832000 , \\ Xinjiang, China
}

\$These authors contributed equally to the present work.

*To whom correspondence should be addressed: Shugang Li, Department of Child, Adolescent Health and Maternal Health, School of Public Health, Capital Medical University, Beijing 100069, China. E-mail: lishugang@ccmu.edu.cn. 
Table S1. Basic characteristics of the included literatures in the meta-analysis

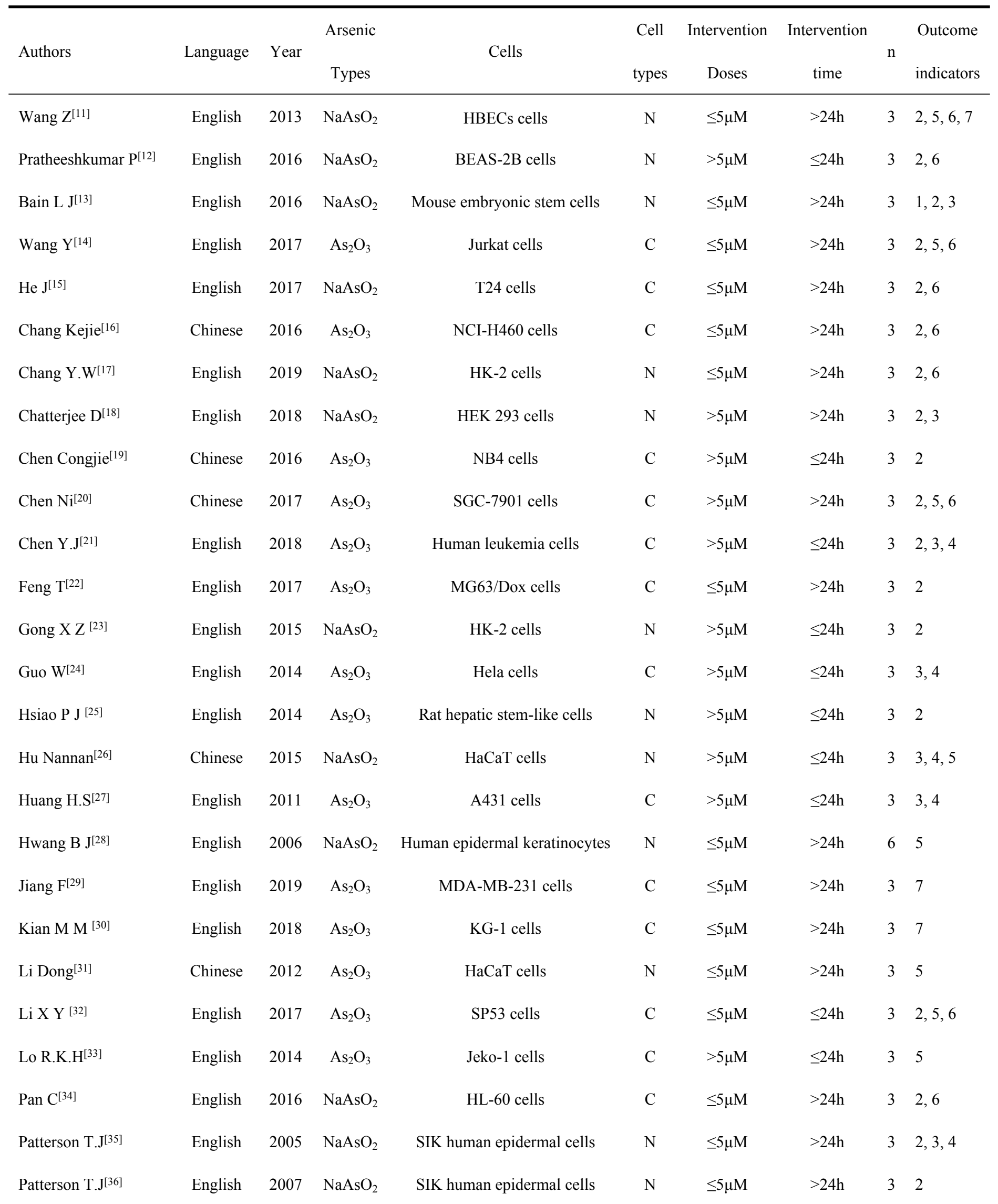




\begin{tabular}{|c|c|c|c|c|c|c|c|c|c|}
\hline Qiu Feng ${ }^{[37]}$ & Chinese & 2017 & $\mathrm{NaAsO}_{2}$ & HN12 cells & $\mathrm{C}$ & $>5 \mu \mathrm{M}$ & $>24 h$ & 5 & 5 \\
\hline Qiu Feng ${ }^{[38]}$ & Chinese & 2017 & $\mathrm{NaAsO}_{2}$ & Tca8113 cells & $\mathrm{C}$ & $>5 \mu \mathrm{M}$ & $>24 h$ & 3 & 2 \\
\hline Sandoval $\mathrm{M}^{[39]}$ & English & 2007 & $\mathrm{NaAsO}_{2}$ & Normal human keratinocytes & $\mathrm{N}$ & $\leq 5 \mu \mathrm{M}$ & $\leq 24 \mathrm{~h}$ & 4 & 4,5 \\
\hline Shao Xiaoyan ${ }^{[40]}$ & Chinese & 2010 & $\mathrm{As}_{2} \mathrm{O}_{3}$ & hFOB1.19 cells & $\mathrm{N}$ & $\leq 5 \mu \mathrm{M}$ & $>24 h$ & 3 & 2 \\
\hline Song Xiaotian ${ }^{[41]}$ & Chinese & 2016 & $\mathrm{NaAsO}_{2}$ & SD rat osteoblasts & $\mathrm{N}$ & $>5 \mu \mathrm{M}$ & $>24 h$ & 6 & $1,2,3$ \\
\hline Srivastava $\mathrm{P}^{[42]}$ & English & 2018 & $\mathrm{NaAsO}_{2}$ & Primary cultured neurons & $\mathrm{N}$ & $>5 \mu \mathrm{M}$ & $\leq 24 \mathrm{~h}$ & 3 & 3,4 \\
\hline $\operatorname{Tan} Z^{[43]}$ & English & 2019 & $\mathrm{As}_{4} \mathrm{~S}_{4}$ & PC12 cells & $\mathrm{C}$ & $>5 \mu \mathrm{M}$ & $\leq 24 \mathrm{~h}$ & 3 & $3,4,6$ \\
\hline Vahidnia $\mathrm{A}^{[44]}$ & English & 2008 & $\mathrm{NaAsO}_{2}$ & HeLa cell & $\mathrm{C}$ & $>5 \mu \mathrm{M}$ & $\leq 24 \mathrm{~h}$ & 6 & 3 \\
\hline Venè Roberta $^{[45]}$ & English & 2014 & $\mathrm{As}_{2} \mathrm{O}_{3}$ & Y79 cells & $\mathrm{C}$ & $>5 \mu \mathrm{M}$ & $\leq 24 \mathrm{~h}$ & 3 & 3,4 \\
\hline Wang $\mathrm{F}^{[46]}$ & English & 2013 & $\mathrm{NaAsO}_{2}$ & SV-HUC-1 cells & $\mathrm{N}$ & $>5 \mu \mathrm{M}$ & $\leq 24 \mathrm{~h}$ & 3 & 7 \\
\hline Wang Hanbin ${ }^{[47]}$ & Chinese & 2008 & $\mathrm{As}_{2} \mathrm{~S}_{2}$ & C6 glioma cells & $\mathrm{C}$ & $>5 \mu \mathrm{M}$ & $\leq 24 \mathrm{~h}$ & 3 & 6 \\
\hline Wang Hongtao ${ }^{[48]}$ & Chinese & 2015 & $\mathrm{As}_{2} \mathrm{O}_{3}$ & HeLa cells & $\mathrm{C}$ & $\leq 5 \mu \mathrm{M}$ & $>24 \mathrm{~h}$ & 3 & 6 \\
\hline Wang Lei ${ }^{[49]}$ & Chinese & 2013 & $\mathrm{As}_{2} \mathrm{O}_{3}$ & Human nephroblastoma cells & $\mathrm{C}$ & $>5 \mu \mathrm{M}$ & $>24 h$ & 5 & 5 \\
\hline Wang $\mathrm{R}^{[50]}$ & English & 2013 & $\mathrm{As}_{2} \mathrm{O}_{3}$ & NB4 cells & $\mathrm{C}$ & $\leq 5 \mu \mathrm{M}$ & $\leq 24 h$ & 3 & 3,4 \\
\hline Wang $\mathrm{R}^{[51]}$ & English & 2018 & $\mathrm{As}_{2} \mathrm{O}_{3}$ & MOLM13 cells & $\mathrm{C}$ & $\leq 5 \mu \mathrm{M}$ & $\leq 24 \mathrm{~h}$ & 3 & 3,4 \\
\hline Wang $\mathrm{X}^{[52]}$ & English & 2012 & $\mathrm{NaAsO}_{2}$ & CRL-1807 cells & $\mathrm{C}$ & $>5 \mu \mathrm{M}$ & $\leq 24 \mathrm{~h}$ & 3 & 2,4 \\
\hline Wang Yuan ${ }^{[53]}$ & Chinese & 2017 & $\mathrm{As}_{2} \mathrm{O}_{3}$ & K562 cells & $\mathrm{C}$ & $>5 \mu \mathrm{M}$ & $>24 \mathrm{~h}$ & 3 & 2,5 \\
\hline Watcharasit $\mathrm{P}^{[54]}$ & English & 2014 & $\mathrm{NaAsO}_{2}$ & SH-SY5Y cells & $\mathrm{C}$ & $>5 \mu \mathrm{M}$ & $\leq 24 \mathrm{~h}$ & 3 & $3,4,7$ \\
\hline $\mathrm{Xu} \mathrm{Wei}{ }^{[55]}$ & Chinese & 2019 & $\mathrm{As}_{2} \mathrm{O}_{3}$ & CAL-27 cells & $\mathrm{C}$ & $\leq 5 \mu \mathrm{M}$ & $>24 \mathrm{~h}$ & 3 & 2,5 \\
\hline Xu Wenchao ${ }^{[56]}$ & Chinese & 2015 & $\mathrm{NaAsO}_{2}$ & HBE cells & $\mathrm{N}$ & $\leq 5 \mu \mathrm{M}$ & $\leq 24 \mathrm{~h}$ & 3 & 2,7 \\
\hline Yadav S [57] & English & 2013 & $\mathrm{NaAsO}_{2}$ & Human mesenchymal stem cells & $\mathrm{N}$ & $\leq 5 \mu \mathrm{M}$ & $>24 \mathrm{~h}$ & 3 & 1 \\
\hline Yan Jianguo $^{[58]}$ & Chinese & 2016 & $\mathrm{As}_{2} \mathrm{O}_{3}$ & NB4 cells & $\mathrm{C}$ & $>5 \mu \mathrm{M}$ & $\leq 24 \mathrm{~h}$ & 3 & 5,6 \\
\hline Yu J[59] & English & 2007 & $\mathrm{As}_{2} \mathrm{O}_{3}$ & SiHa cells & $\mathrm{C}$ & $\leq 5 \mu \mathrm{M}$ & $>24 \mathrm{~h}$ & 3 & 2 \\
\hline Zhai B ${ }^{[60]}$ & English & 2015 & $\mathrm{As}_{2} \mathrm{O}_{3}$ & Huh7 cells & $\mathrm{C}$ & $\leq 5 \mu \mathrm{M}$ & $>24 h$ & 3 & $3,4,5$ \\
\hline Zhang Hui[61] & Chinese & 2007 & $\mathrm{As}_{2} \mathrm{O}_{3}$ & LoVo cells & $\mathrm{C}$ & $>5 \mu \mathrm{M}$ & $>24 h$ & 3 & 7 \\
\hline Zhang $\mathrm{L}^{[62]}$ & English & 2018 & $\mathrm{As}_{2} \mathrm{O}_{3}$ & MGC803 cells & $\mathrm{C}$ & $\leq 5 \mu \mathrm{M}$ & $\leq 24 \mathrm{~h}$ & 3 & 7 \\
\hline Zhang $\mathrm{L}^{[63]}$ & English & 2015 & $\mathrm{As}_{4} \mathrm{~S}_{4}$ & MGC803 cells & $\mathrm{C}$ & $\leq 5 \mu \mathrm{M}$ & $\leq 24 \mathrm{~h}$ & 3 & 2,7 \\
\hline Zhang $\mathrm{P}^{[64]}$ & English & 2017 & $\mathrm{As}_{2} \mathrm{O}_{3}$ & U937 cells & $\mathrm{C}$ & $\leq 5 \mu \mathrm{M}$ & $>24 h$ & 3 & $2,5,6$ \\
\hline Zhang $\mathrm{Y}^{[65]}$ & English & 2016 & $\mathrm{As}_{2} \mathrm{O}_{3}$ & Human aortic endothelial cells & $\mathrm{N}$ & $>5 \mu \mathrm{M}$ & $\leq 24 \mathrm{~h}$ & 3 & 3,4 \\
\hline
\end{tabular}




\begin{tabular}{|c|c|c|c|c|c|c|c|c|c|}
\hline Zheng $\mathrm{L}^{[66]}$ & English & 2016 & $\mathrm{As}_{2} \mathrm{O}_{3}$ & PC3 cells & $\mathrm{C}$ & $>5 \mu \mathrm{M}$ & $\leq 24 \mathrm{~h}$ & 3 & $2,3,4,6$ \\
\hline Zhou L ${ }^{[67]}$ & English & 2008 & $\mathrm{As}_{2} \mathrm{O}_{3}$ & CZ-1 cells & $\mathrm{C}$ & $\leq 5 \mu \mathrm{M}$ & $\leq 24 \mathrm{~h}$ & 3 & 2 \\
\hline
\end{tabular}

Note: N, normal cells; C, cancer cells; n, number within the experimental and control group; Outcome indicators: the key molecules in the wnt/ $\beta$-catenin signaling pathway. These indicators can reflect the influence of arsenic on wnt $/ \beta$-catenin signaling pathway. Outcome indicators: 1. wnt3a protein: a kind of important activating signal molecule of wnt/ $\beta$-catenin signaling pathway; 2 . $\beta$-catenin: the core molecule of wnt/ $\beta$-catenin signaling pathway, which plays a regulatory role in downstream molecules; 3 . GSK-3 $\beta$ (glycogen synthase kinase $3 \beta$ ): one of the rate-limiting enzymes of glycogen synthesis and a negative regulator of wnt/ $\beta$-catenin signaling pathway; 4. p-GSK-3 $\beta$ (Ser9) (glycogen synthase kinase-3 $\beta$ phosphorylated at serine 9): a inactivation form of GSK-3 $\beta$; 5. cyclinD1: a downstream molecule of wnt/ $\beta$-catenin signaling pathway, which can regulate cell cycle; 6 . c-myc (a kind of protooncogene): a downstream molecule of wnt/ $\beta$-catenin signaling pathway, which can promote cell division, make cells proliferate infinitely and obtain immortalization function. It is also related to the occurrence and development of many kinds of tumors; 7. VEGF(vascular endothelial growth factor): a downstream molecule of wnt/ $\beta$-catenin signaling pathway, which can promote the mitosis of vascular endothelial cells. 